\title{
Influence of technological factors of blade processing on the forming of the defect layer
}

\author{
Julius L. Tchigirinsky,"* and Trong Ngo Quang ${ }^{1}$ \\ 1 “Technology of Machinery” Department, Volgograd State Technical University, 28, Lenin's av., Volgograd, Russia, 400005
}

\begin{abstract}
Identified the interrelationships between the depth of the surface layer with modified physicalmechanical properties (defective or work-hardened or fill hard layer), the parameters of cutting process, and the properties of materials of tool and workpiece. Justified the necessity of research the processes of formation the properties of the machined surface from the standpoint of the thermo-physics of the cutting process.
\end{abstract}

The formation of subsurface deformation is an attribute of the wedge cutting process. The subsurface deformation significantly affects on the resistance to corrosion and other performance properties of the product. A number of researchers $[2,3,5]$ notes that in the surface layer, in addition to changes in physical and mechanical characteristics of the material, such as microhardness, strength and ductility may also change in the crystal structure. As a rule, the condition of the subsurface deformation is evaluated by two basic indicators: the depth and degree of hardening. The degree of hardening is defined [2] as the change in the microhardness of the surface layer in relation to the original material.

In the studies of A. D. Makarov, L. G. Odintsova and other authors $[2,3,12]$ identified the main reasons for the formation of the layer with modified physical and mechanical properties - the combined effects of cutting forces and increased temperature induced during a machining. At research by N. V. Talantov [4] and his students proved that the formation of the deformed layer is greatly influenced by the friction at the rake surface and rear surface of the tool, forces and temperature processes in the primary shear zone, temperature and diffusion processes of the "blank-tool" and "chip-tool". All of these factors are the result of the influence of independent technological conditions of a metal cutting process: physical-mechanical properties of materials of the tool and the workpiece, the method of forming, cutting conditions (cutting speed, depth of cut, feed) and the geometric parameters of the cutting wedge.

When considering the microstructure of the depth of the defective layer (Fig. 1), it is possible to distinguish three main zones. In subsurface layer (A), the workpiece material is maximally loaded with both force and temperature influences. As a consequence, the change of the microstructure in this layer is clearly pronounced, in comparison with the deeper layers of the deformed layer (B) and in comparison with the core of the workpiece material. This is evident from a comparison of the size and shape of the crystals in Fig. 1 - considerable differences in size and shape of the crystals, and clearly shows the direction of the impact cutting forces.

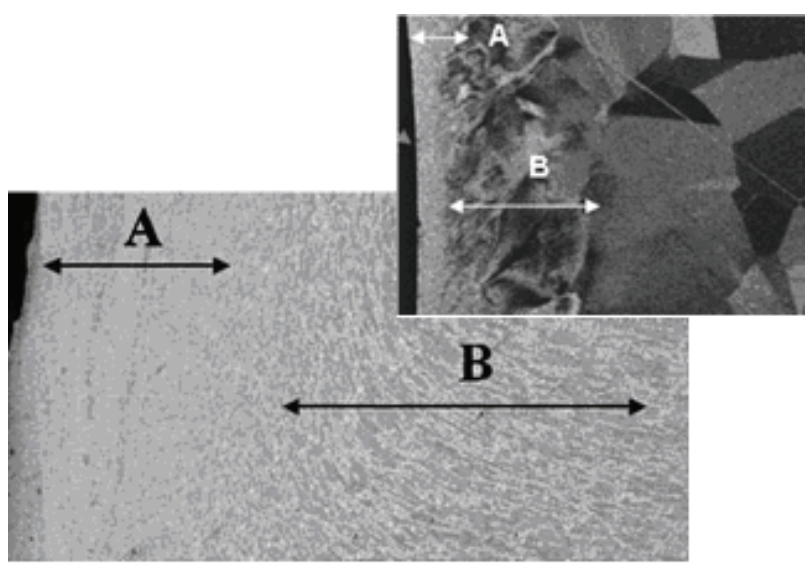

Fig. 1. Microstructure of subsurface deformation $[9,11]$

The change of the microstructure in the layer (A) is significant, because force is enhanced by high temperatures on the surface finish. In layer (B), the level of temperature-force influence is not so significant. As a consequence, the change of the microstructure of the material and the size of the crystals is less pronounced than in the layer (A), which indicates a smaller degree of plastic deformation of the material. The intensity of deformation and notable changes in the microstructure gradually decrease to the equilibrium state of the core material of the workpiece.

In some cases, when a certain combination of physical and mechanical properties of the contact pairs "toolworkpiece" and cutting parameters, a layer with reduced mechanical properties can be formed on the surface finish [11]. This phenomenon is observed as a result of high cutting speeds with a low thermal conductivity of cutting tools, Such conditions promote intensive heating of the surface finish, which ultimately can lead to the appearance of microcracks on the surface of the product and reduce its performance properties [11]. From the analysis, it follows that the temperature-force conditions

\footnotetext{
* Corresponding author: Julio-Tchigirinsky@,yandex.ru
} 
of processing are critical in the study of properties and regularities of formation of the defect layer.

Classification of the factors affecting the process of formation of the defect layer is shown in Fig. 2.

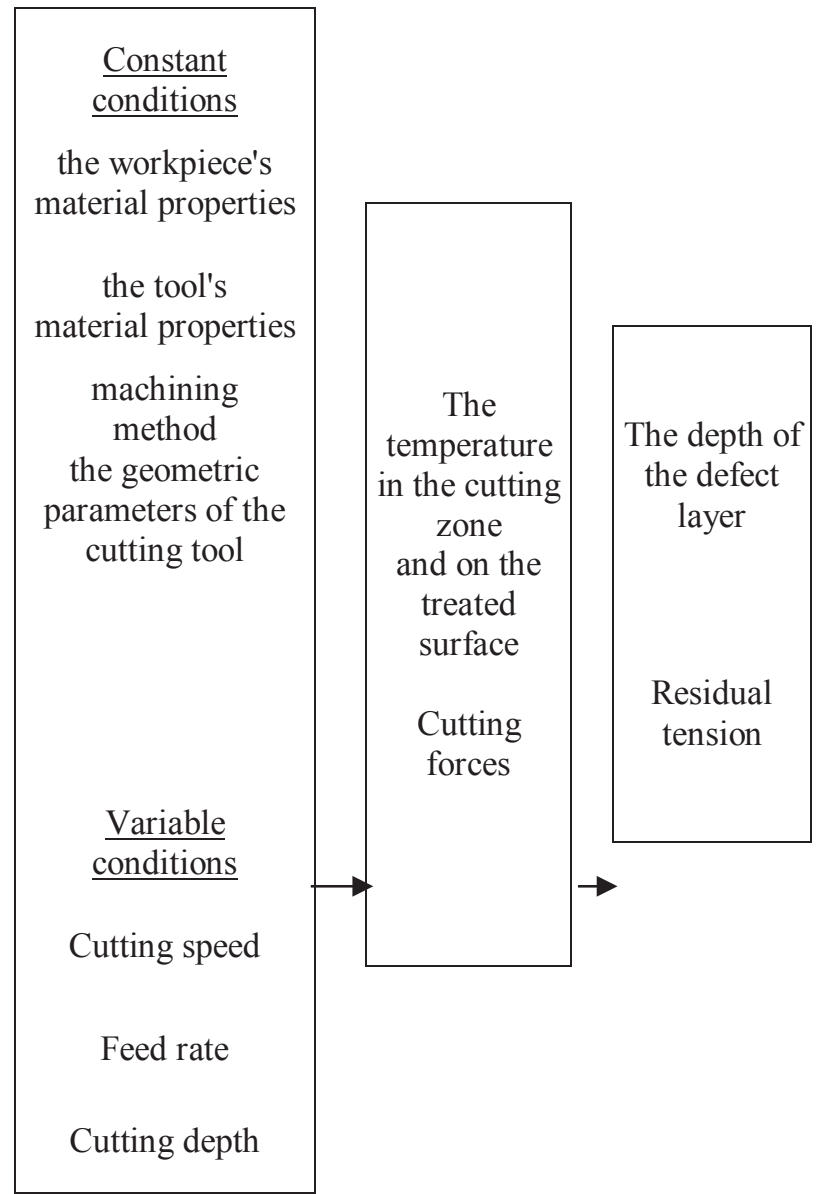

Fig. 2. Parameters that affect the depth of the defective layer

Investigations $[2,12]$ have established the influence of the cutting speed and tool wear on the depth of the hardened layer, the degree of influence wear is much greater. This is confirmed by the studies of N. V. Talantov [4] and the conclusion about the influence of cutting speed on the regularity of the flow of force and temperature processes in the processing zone and, ultimately, the intensity of the tool wear. Experimentally [2] determined the relationship between cutting speed and depth (hc) of the defect layer, and the degree (N \%) of deformation (Fig. 3). In the low cutting speeds (Section I) the depth and degree of hardening decrease monotonically with increasing cutting speed. This is due to the increasing temperature [2], a gradual change in the form of a contact interaction, and the transition from cutting with the build-up [4]. To the formation of stagnant zones (Section II) on the rake surface. Continue to increase the cutting speed, due to the combined effects of the processes of strain hardening and temperature softening, the character of the depth and degree deformation of the curves changes, a plastic contac is formed on the rake surface (Section III). The increase in the intensity of tool wear and contributes to the growth of the chamfer of the flank wear of the tool, i.e., to increase the frictional forces and temperatures.
The results of experimental studies and conclusions of A. D. Makarov [2] that defines the section II (cutting speed $20 \ldots 50 \mathrm{~m} / \mathrm{min}$ ) as the range of optimal temperatures are in good agreement with the concept of "transition cutting speeds" [4] in which there is a change of types of contact interaction.

The higher degree of influence of tool wear, compared with the cutting speed, is explained by the fact that tool wear, as "explanatory" factor defines the total influence of cutting speed and temperature-deformation processes in the defomed chip.

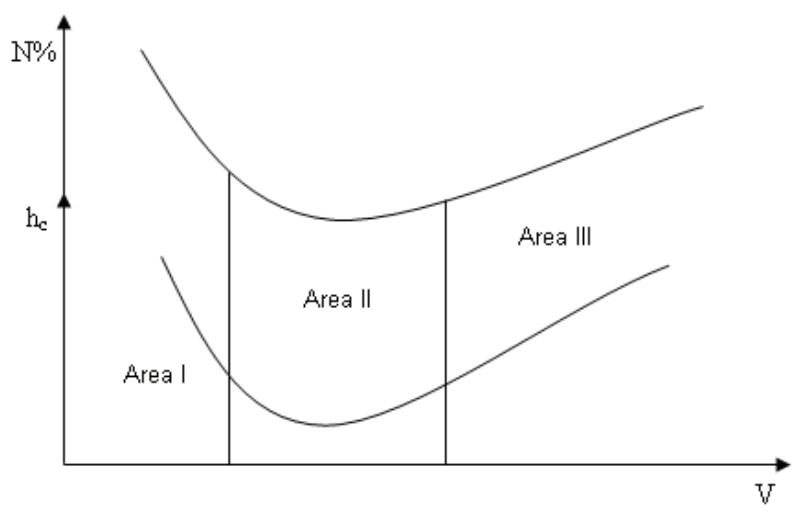

Fig. 3. Effect of cutting speed on depth and degree of defective layer

The effect of the feed on surface layer shown in Fig. 4. Curve (I) shows the patterns of change in the depth and degree of deformation in the range of cutting speeds corresponding to the optimal temperature [2] (Section II, Fig. 3)

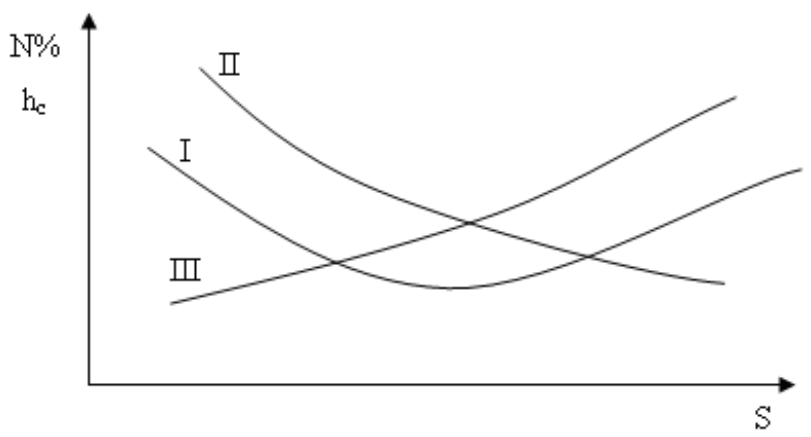

Fig. 4. Effect of depth feed and degree of defective layer

Curve (II) corresponds to the range of low cutting speeds - the total tension state of the surface layer decreases with increasing feed rate. Curve (III) determines the influence of feed rate on the depth and degree of deformation of the surface layer in the range of high cutting speeds (Section III, Fig. 3), corresponding to the plastic contact of the tool and the chip.

The decrease the rake angle $\gamma$, the dearance angle $\alpha$ and increasing the radius of the rounding edge of the cutting edge $\rho$ increases the effect of friction forces at the rake and flank surfaces and the tip of the tool, increasing the shear angle $\beta$, which ultimately increases the depth of the defect layer. 
The two mechanisms for the formation of the hardened layer on the surface finish is indicated by studies [6] aimed to study the effect of wear-resistant coatings: the depth and degree of deformation in the surface layer are determined by the friction on contact surfaces and thermophysical characteristics of the tool. The change of friction coefficient on the rake surface of the tool leads to the change of the chip reduction coefficient, which affects the intensity of the temperature in the cutting zone. Also, the intensity of heat release depends on the thermal conductivity of the tool material. The coefficient of friction at the flank surface of the tool determines the degree of stresses in the contact zone and, consequently, the degree of deformation of the hardened layer. Studies [2] show that there are clear differences in the depth and degree of deformation when machining with tools made of hard alloys with different thermal conductivities WC 92-Co 8, TiC 5-WC 85-Co 10, TiC 14-WC 78-Co 8.

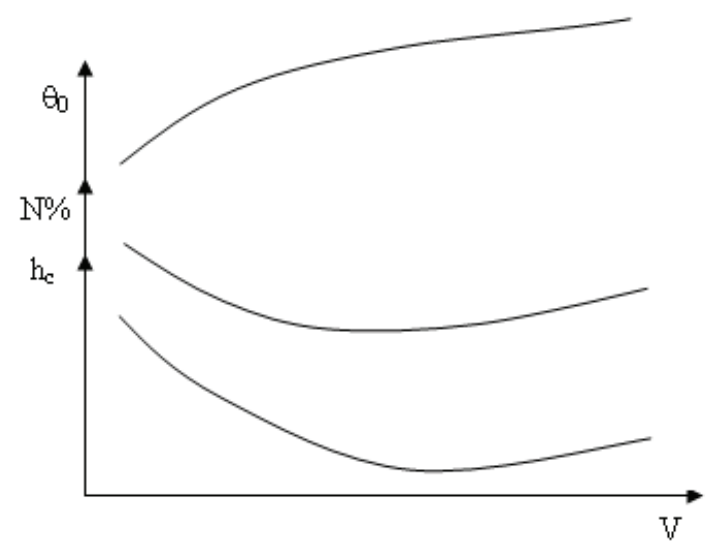

Fig. 5. Effect of cutting speed on depth and degree of defective layer and average contact temperature [2]

The results of investigations of the state of the surface layer in the processing of heat-resistant deformable alloys shown (Fig. 5) that the depth and the degree of deformation reaches the minimum values in the range of medium (Fig. 3, section II) cutting speeds, while the temperature dependence in the contact zone is monotonous.

Given that the thermophysical characteristics of steels change $[1,2,10]$ depending on the degree of deformation, it is possible to say that the regularities of formation of the surface layer are not unique. Determination of the relationship between the characteristics of the hardened surface layer only from the elements of cutting conditions can lead to incorrect conclusions.

The analysis allows to make preliminary conclusions about the importance of the effect of thermal processes in the contact zone "tool-workpiece" on the properties of the surface layer of machined parts, i.e., depending on the depth and degree of deformation of the hardened layer from the thermophysical characteristics of structural and tool materials.

To check the formulated hypotheses, a multivariate regression analysis [8] of the results of experimental [9, $11,12,13]$ studies of the milling end mills was carried out. As the parameter of the analyzed state of the surface layer of articles made of titanium (Ti-6Al-4V) alloy, the arithmetic mean deviation of the microroughness $\mathrm{Ra}$ is considered.

For contact pair titanium alloy (Ti-6Al-4V) - is a single-carbide with wear-resistant coating (TiN mill end $\phi 12 \mathrm{~mm}$ ); cutting speed $\mathrm{V}=[120 / 160 / 200] \mathrm{m} / \mathrm{min}$, depth of cut $\mathrm{t}=[0,20 / 0,35 / 0,5] \mathrm{mm}$, feed $\mathrm{S}=[0,10 / 0,12 / 0,14]$ $\mathrm{mm} /$ tooth - results of statistical analysis are presented in Table. 1.

Table 1. The degree of influence of technological factors on the height of microroughness (Ti-6Al-4V-TiN)

\begin{tabular}{|c|c|c|c|}
\hline \multirow{2}{*}{$\begin{array}{c}\text { Parameter } \\
\text { Specification model }\end{array}$} & \multicolumn{3}{|c|}{ Model specification } \\
\hline & Linear & Power & Exponential \\
\hline \multicolumn{4}{|c|}{ Non-correlated (independent) factors } \\
\hline $\begin{array}{l}\text { Random factors } \\
\text { (uncertainty) }\end{array}$ & $-0,196$ & 0,004 & 0,004 \\
\hline Cutting depths $(t)$ & 0,063 & 0,028 & 0,027 \\
\hline Feed rate $(S z)$ & 0,634 & 0,609 & 0,602 \\
\hline Cutting speed $(V)$ & $-0,503$ & $-0,552$ & $-0,551$ \\
\hline \multicolumn{4}{|c|}{$\begin{array}{l}\text { Pseudo-factors, taking into account the interactions } \\
\text { between independent factors }\end{array}$} \\
\hline $\begin{array}{l}\text { Cutting depths }- \text { feed } \\
\text { rate (cross-sectional } \\
\text { area of the cut) }\end{array}$ & $-0,114$ & 0,096 & $-0,117$ \\
\hline $\begin{array}{l}\text { Cutting depths - } \\
\text { cutting speed }\end{array}$ & $-0,169$ & 0,002 & 0,006 \\
\hline $\begin{array}{l}\text { Feed rate - cutting } \\
\text { speed }\end{array}$ & 0,077 & $-0,081$ & 0,093 \\
\hline \multicolumn{4}{|c|}{ Error estimation and model adequacy } \\
\hline Standard deviation & 3,532 & 3,532 & 3,532 \\
\hline Fisher's criterion & 5,548 & 13,049 & 9,124 \\
\hline Model adequacy, $\%$ & 99,90 & 99,90 & 99,90 \\
\hline Relative error, $\%$ & 3,62 & 1,31 & 2,50 \\
\hline
\end{tabular}

The coefficients of the regression models (Table. 1) built in the normalized coordinate space with allowance for the implementation of a standard Gauss-Markov, allow to judge about the degree of influence of explanatory variables on the behavior of the response function. For analysis of the selected three models, the most often considered in technology, specifications. Based on an assessment of modeling error adopted power model.

Positioning the three most important explanatory variables (technological factors, the arguments of the model) in descending order of the absolute values of the regression coefficients of the normalized model, we get the following range: feed, cutting speed, chip thickness. From the above discussion, it follows that the formation of the defect layer is the result of a direct effect of temperature-force processes in the contact zone "toolworkpiece", the depth of the defect layer are determined by the combined effects of input processing parameters [7]: cutting conditions, machining method, parameters of the cutting tool, physical-mechanical properties of contacting materials of the tool and the workpiece. 


\section{Conclusion}

Analysis of the results of the regression analysis allows: First, confirm the traditional view of the geometric nature of the microrelief of the surface finish - the most significant factor is the feed rate;

Second, to make a conclusion about the significant influence of thermal processes in the contact zone "toolworkpiece" on the state of the surface layer, because even for geometric characteristics $(\mathrm{Ra})$ of the surface layer is important effect of the size of the heat source;

Thirdly, to formulate directions for further research: a more subtle directional study of the temperature-force processes in the shear zone in the contact zone "toolworkpiece" to build a physical model of the formation of modified physical-mechanical properties of the surface layer and the determination of quantitative characteristics of the complex interrelationships between the state of the surface layer with processing conditions to control the performance properties of the surfaces finish.

\section{References}

1. A. M. Rozenberg, A. N. Eremin, Elements of the theory of the process of metal cutting (Moscow.Sverdlovsk : Machgiz, 1956)

2. A. D. Makarov, Optimization of cutting processes (Moscow : Machinery Publishing, 1976)

3. L. G. Odintsov, Hardening and finishing the parts of machines by surface plastic deformation: Handbook (Moscow : Machinery Publishing, 1987)

4. N. V. Talantov, Fizicheskie osnovy protsessa rezaniya, iznashivaniya i razrusheniya instrumenta (Physical Principles of Cutting and Tool Wear and Failure) (Moscow : Machinery Publisher, 1992)

5. M. E. Blanter, The metallography and heat treatment (Moscow: Machgiz, 1963)

6. V, P. Tabakov, A. V. Chihranov, Wear-resistant coating of cutting tools operating under conditions of continuous cutting (Ulyanovsk : UISTU, 2007)

7. A. I. Khaimovitch, A. V. Kuznetcov, Analytical modeling of power mode high-speed milling of material with viscoplastic hardening, Vestnik of Samara University. Aerospace engineering, technology and engineering, № 5-2 (36), P. 167-172 (2012)

8. Ju. L. Tchigirinsky, Mathematical methods for process control of machining: monography/ Volgograd State Technical University. Volgograd. - 139 p. (2010)

9. G. A. Oosthuizen, K. Nunco, P. J. T. Conradie, D. M. Dimitrov, The effect of cutting parameters on surface integrity in milling Ti6Al4V, South African Journal of Industrial Engineering. Vol 27 (4), p. 115123. (2016)

10. I. N. Kozachukhnenko,

A. A. Bondarev, D. V. Krainev, Yu. N. Polyanchikov, H. V. Khodjamberdyev, The justification to improve the surface quality when machining with pre- hardening heat-resistant steel 30CrMo4 from the position of the dislocation view, Bull. VSTU, no. 1 (156), p. 6-19 (2015)

11. Pete Crawforth. Towards a Micromechanistic Understanding of Imparted Subsurface Deformation During Machining of Titanium Alloys (University of Sheffield, 2014)

12. Zhou Jinming, Volodymr Bushlya, Ru Lin Peng, JanEric Stahl, Identification of Subsurface Deformation in Machining of Inconel 718, Trans Tech Publications, Switzerland, Vols. 117-119, pp 16811688 (2011)

13. Liu Chunjing, Tang Dunbing, He Hua, Chen Xingqiang, Prediction of surface roughness for end milling titanium alloy using modified particle swarm optimization LS-VM, Transactions of Nanjing University of Aeronautics \& Astronautics, Vol. 30 No.1, p. 53-61 (2013) 